\title{
Configurações reticulares e inovação: reflexões acerca da efetividade de padrões estruturais distintos
}

\author{
Reticular settings and innovation: reflections about the \\ effectiveness of different structural patterns
}

Cristiano de Oliveira Maciel[a], Marcos de Castro ${ }^{[\mathrm{b}]}$

[a] Doutorando em Administração pelo Programa de Pós-Graduação em Administração da Pontifícia Universidade Católica do Paraná (PUCPR), professor do curso de Administração da PUCPR, Curitiba, PR - Brasil, e-mail: crmaciel.adm@gmail.com

[b] Doutorando em Administração pela Universidade Federal do Paraná, professor assistente do Departamento de Administração da Universidade Estadual do Centro-Oeste, (UNICENTRO), Guarapuava, PR - Brasil, e-mail:

marcosdecastroms@yahoo.com.br

\section{Resumo}

As pesquisas que utilizam a perspectiva das redes sociais têm debatido em relação aos méritos de diferentes formas e padrões estruturais de redes como determinantes dos resultados dos relacionamentos. No escopo dessa discussão surge a inovação como consequência de padrões estruturais distintos, de forma que relacionamentos cooperativos e competitivos contribuem para o surgimento de novos produtos, processos e tecnologias. 0 objetivo desse ensaio teórico é discutir de que forma diferentes configurações de redes interorganizacionais e diferentes padrões estruturais facilitam ou limitam o surgimento de inovações. Para tanto, efetuou-se um levantamento bibliográfico com vistas a verificar como a literatura relaciona a inovação ao padrão estrutural das redes. Mais especificamente, as origens, as possibilidades e as formas de inovação são consideradas nas abordagens dos laços fracos (GRANOVETTER, 1973) e dos buracos estruturais (BURT, 1992). 0 artigo encerra destacando a necessidade de pesquisas adicionais sobre o efeito da forma e padrões estruturais aliados aos aspectos dinâmicos e contextuais das redes, pois considerando o conteúdo das configurações reticulares, e a sua constante mudança e evolução, é possível inferir que focalizar somente a estrutura pode comprometer demasiadamente a explicação do fenômeno da inovação.

Palavras-chave: Redes. Estrutura. Inovação.

\footnotetext{
Abstract

The research that uses the perspective of social networks has debated about the merits of different shapes and structural patterns of networks as determinants of the outcomes of relationships. The scope of this discussion takes innovation as a result of different structural patterns, so that cooperative and competitive relationships contribute to the emergence of new products, processes and technologies. The aim of this essay is to discuss how different configurations of interorganizational networks and different structural patterns facilitate or constrain
} 
the emergence of innovations. For this, was carried out a bibliographic research in order to verify how the literature relates the structural pattern of networks with the innovation. More specifically, the origins, possibilities and forms of innovation were considered in the approaches of weak ties (GRANOVETTER, 1973) and structural holes (BURT, 1992). The article concludes emphasizing the need for additional research on the effect of form and structural patterns allies to contextual and dynamic aspects of networks, because considering the content of networks, and its constant change and evolution, is possible to infer that the focus only on structure can compromising too much the explaining about the phenomenon of innovation.

Keywords: Networks. Structure. Innovation.

\section{Introdução}

Em face da complexidade e da intensificação das pressões ambientais tem ocorrido um crescente deslocamento da ênfase no gerenciamento de portfólios de negócios e das competências das organizações para a construção e gerenciamento dos relacionamentos interorganizacionais. Esse movimento tem contribuído para a formação das redes estratégicas e outras formas organizacionais (GULATI; NOHRIA; ZAHEER, 2000; JARILLO, 1988; SYDOW; WINDELER, 1998; VENKATRAMAN; SUBRAMANIAM, 2002).

As redes interorganizacionais consistem em uma forma eficaz para o alcance de competitividade nos mercados por meio de um complexo ordenamento de relacionamentos, em que as organizações estabelecem inter-relações sob diferentes formas, em diferentes contextos e a partir de expressões culturais diversas (CASTELLS, 1999). Tal fenômeno tem despertado muito interesse entre as organizações, pois, de acordo com Balestrin e Vargas (2004, p. 204), "a configuração em rede promove ambiente favorável ao compartilhamento de informações, de conhecimentos, de habilidades e de recursos essenciais para o processo de inovação". Além disso, os relacionamentos cooperativos apresentam uma importância estratégica em ambientes competitivos, sobretudo por facilitar a sinergia de esforços entre as organizações na direção de objetivos comuns (BALESTRIN; VARGAS, 2004).

Dentro da temática dos relacionamentos interorganizacionais, a literatura tem destacado a importância das redes interorganizacionais para o desenvolvimento econômico e social, direcionando o foco de muitos estudos para questões relacionadas ao seu reflexo na geração de empregos, renda e tributos. Atestando tal assertiva, Scherer-Warren (1999) considera que as redes interorganizacionais são uma estratégia de ação coletiva, que visa uma transformação social em um determinado local. Dessa forma, as redes interorganizacionais são vistas como formas de organização e de ação dos atores sociais, visando promover uma mudança, podendo ser de caráter econômico ou social (ANDION, 2003).

Andion (2003), ao focar a importância das redes interorganizacionais para a promoção do desenvolvimento destaca que, entre outras consequências, elas permitem aproveitar mais racionalmente os recursos disponíveis; geram economias de um número maior de projetos permitindo acelerar o processo de desenvolvimento; possibilitam ir além das ações pontuais, fazendo com que os atores se engajem em objetivos de transformação de longo prazo e construam estratégias integradas de ação; e permitem reflexão e busca de soluções comuns aos problemas econômicos e sociais da coletividade, promovendo uma maior participação.

Souza (1995) reconhece a importância das redes interorganizacionais destacando a sua relevância para o estímulo à livre-iniciativa e à capacidade de inovação; o alcance de relações de trabalho mais harmoniosas; a contribuição para a geração de novos empregos e a absorção de mão de obra, seja pelo crescimento das organizações já existentes, seja pelo surgimento de novas; efeito amortecedor dos impactos do desemprego; efeito amortecedor das flutuações na atividade econômica; manutenção de certo nível de atividade econômica em determinadas regiões; contribuição para a descentralização da atividade econômica, em especial na função de complementação das grandes organizações; e potencial de assimilação, adaptação, introdução e, algumas vezes, geração de novas tecnologias de produto e de processo. Para o autor, isso ocorre em função da dinâmica de 
cooperação que as redes interorganizacionais podem gerar, na qual informações, competências, entre outros recursos, são compartilhados por meio de um processo em que tanto as organizações quanto os indivíduos são beneficiados, representando, assim, uma das formas mais eficientes de promoção do desenvolvimento local.

A inovação tem sido citada como um dos principais benefícios gerados pelas configurações reticulares (BALESTRIN; VARGAS, 2004; BRASS et al., 2004; POWELL; KOPUT; SMITH-DOERR, 1996; SODA; USAI; ZAHEER, 2004) em virtude do maior fluxo de informações, conhecimentos e competências entre os atores que integram essa forma organizacional. Porém, diferentes padrões estruturais podem resultar em diferentes níveis e tipos de inovação em função da forma com que as informações e conhecimentos fluem por meio dos relacionamentos (BRASS et al., 2004).

Diante do exposto, o objetivo deste trabalho é discutir os diversos padrões estruturais que as redes interorganizacionais podem assumir e a contribuição de tais padrões para a inovação. Para tanto, o trabalho está estruturado da seguinte forma: primeiramente, são apresentadas as diretrizes metodológicas que guiaram a construção do artigo. Na sequência discutem-se as configurações reticulares com especial ênfase no seu aspecto estrutural. Num terceiro momento, apresenta-se o conceito e os tipos de inovação para, em seguida, discutir-se a inovação como resultado dos diferentes padrões estruturais das configurações reticulares. Por fim, têm-se as conclusões do ensaio teórico.

\section{Diretrizes metodológicas}

0 presente ensaio foi elaborado a partir de uma revisão integrativa (integrative review) e estabelecimento de proposições. Esse modo de revisão, de acordo com Neuman (1997), é adequado quando o pesquisador busca sintetizar o conhecimento atual sobre determinado tópico. A delimitação dos artigos ocorreu por meio da escolha de trabalhos seminais da área de redes, como os trabalhos de Granovetter (1985) e Burt (1992) e identificação de trabalhos sobre inovação que recorreram a esses artigos. A partir desse conjunto de artigos foram selecionados aqueles que apresentavam argumentos mais consistentes sobre a temática da presente pesquisa. Na sequência, a revisão integrativa (NEUMAN, 1997) permitiu a articulação de relações e conceitos que foram apresentados nas proposições.

\section{Configurações reticulares}

A estruturação de novas formas organizacionais em redes e a adoção de estratégias de cooperação têm renovado o interesse pelo estudo dos relacionamentos interorganizacionais. A formação desses arranjos tem sido compreendida à luz de várias tipologias a respeito dos condicionantes dos relacionamentos. Oliver (1990), por exemplo, propõe uma síntese das razões subjacentes ao estabelecimento de interações entre organizações. De acordo com a proposta da autora existem seis determinantes mais gerais para a construção das conexões entre organizações: necessidade, assimetria, reciprocidade, eficiência, estabilidade e legitimidade.

As combinações entre esses e outros fatores têm contribuído para um aumento na formação das redes estratégicas, que operam como formas híbridas entre mercados e hierarquias (GULATI; NOHRIA; ZAHEER, 2000; JARILLO, 1988). Mais especificamente, uma rede estratégica consiste em uma forma organizacional que se estrutura a partir de relacionamentos cooperativos e competitivos, no qual os atores atuam com certo grau de reflexividade e que opera em uma lógica diferente de mercados e hierarquias em razão de um alto nível de embeddedness estrutural e institucional com relacionamentos relativamente complexos e recíprocos (GULATI; NOHRIA; ZAHEER, 2000; JARILLO, 1988; POWELL; SMITH-DOERR, 1994; SYDOW; WINDELER, 1998; GULATI; NOHRIA; ZAHEER, 2000).

Esse fenômeno tem sido tratado em diversos aspectos sob a égide do conceito mais amplo de embeddedness (GRANOVETTER, 1985). A consideração de que a ação organizacional é imersa em redes sociais tem conduzido a um maior direcionamento para essa questão no âmbito das relações no interior e entre organizações. Essa visão, quando confrontada com teorias mais estáticas ou estruturalistas, traz as vantagens de uma análise mais dinâmica na apreensão do estabelecimento de estruturas e estratégias nas organizações.

Redes de relações entre indivíduos em diferentes organizações e entre organizações em um campo são críticas na explicação de como organizações 
adotam estruturas similares e perseguem estratégias comuns (POWELL; SMITH-DOERR, 1994, p. 369, tradução nossa).

A centralidade do conceito de redes sociais é bastante evidente na análise das relações interorganizacionais (OLIVER, 1996), pois é por meio das redes sociais que ocorrem as trocas de informações e recursos das organizações com o ambiente (BURT, 1992).

Nos estudos organizacionais, o conceito de redes é aplicado tanto na dimensão intraorganizacional quanto na dimensão interorganizacional. Como afirmam Powell e Smith-Doerr (1994), os relacionamentos informais estão no centro da vida política das organizações. Tal assertiva revela a importância das redes sociais no interior das organizações assim como na relação com suas constituências externas (i.e. audiências institucionais).

Focalizando mais especificamente o problema do embeddedness, Granovetter (1985) defende que tanto o comportamento dos atores sociais quanto as instituições são afetados pelas relações sociais. 0 conceito de embeddedness, no que concerne ao comportamento das organizações, pode ser entendido como o imbricamento ou imersão da atividade econômica e organizacional dos agentes num contexto mais amplo de relações sociais.

0 argumento por trás do conceito é que o comportamento e as instituições estão de tal forma imersos em processos de relações sociais, de forma que tratá-los como aspectos independentes levaria a sérias limitações na apreensão da dinâmica das atividades organizacionais (GRANOVETTER, 1985).

Como exemplo da imersão do comportamento econômico nas relações sociais, Granovetter (1985) lança uma crítica a Teoria dos Custos de Transação (TCT) do economista Oliver Williamson (1985). De acordo com Granovetter (1985), essa teoria assume o comportamento econômico do agente como auto-interessado e minimamente influenciado pela rede social. Em princípio, Granovetter (1985) preocupou-se em oferecer uma colaboração teórica para o conceito de embeddedness que permeia a ação econômica. Para o autor, a sociologia contemporânea tem uma concepção de homem supersocializada, ou seja, as pessoas são muito sensíveis às opiniões dos outros e obedientes a sistemas de normas desenvolvidos consensualmente. Por outro lado, na economia, existe uma concepção utilitarista de homem como indivíduo, subsocializado mas, também, atomizado.
Na economia clássica e neoclássica as relações sociais são tratadas como um fator limitante impedindo a competitividade dos mercados. A atomização social é um pré-requisito à competição perfeita. Todavia, na comparação entre as duas perspectivas, tanto a sociologia quanto a economia têm em comum uma concepção de ação conduzida por atores atomizados, ou seja, a ação realizada é sempre unilateral, dependente apenas do indivíduo a quem a ação é atribuída.

$\mathrm{Na}$ tentativa de se ir além dessa abordagem atomizada, a imersão estrutural reflete a estrutura dos relacionamentos interorganizacionais, por exemplo, a posição dos atores na rede e outras características da estrutura dos relacionamentos (embeddedness estrutural), enfatizados principalmente por Granovetter (1973) e Burt (1992). Nessa ótica de análise, com frequência o interesse do pesquisador recai no entendimento da natureza dos laços entre atores de uma rede e sua capacidade de desenvolver capital social. Granovetter (1973), por meio de sua metáfora dos laços fracos, defende que tais laços, caracterizados por baixos índices de intensidade emocional, tempo, intimidade e reciprocidade, representam o fator crucial na obtenção de novas informações e oportunidades. Já Burt (1992) dá maior ênfase em outra propriedade das redes, as falhas estruturais. Para o autor a taxa de retorno de uma organização é atrelada à estrutura social da sua arena competitiva, e a rede de contatos de uma organização e sua posição em tal rede dá origem a vários tipos de capital, sobretudo, o capital social.

Mas a despeito da ampla citação do argumento do embeddedness apresentado por Granovetter (1985), em seu trabalho não ficam explícitas as formas pelas quais as relações sociais afetam a ação econômica. 0 que é mais claramente estabelecido naquele artigo são apenas as diferenças nas estruturas conceituais que concorrem na explicação do comportamento econômico (UZZI, 1997). "O estabelecimento central que a ação econômica é imersa em, mais ou menos permanentes, laços sociais que às vezes facilitam e às vezes prejudicam as trocas, sofre de uma indeterminação teórica". (UZZI, 1997, p. 35, tradução nossa). As implicações do argumento de Granovetter (1985) são vistas como indeterminadas em face do desequilíbrio entre proposições relativamente específicas de teorias econômicas e um estabelecimento de maior espectro em relação à forma pela qual os laços sociais afetam a ação econômica. 
A partir daí, Uzzi (1997) argumenta em favor da diferenciação entre formas de imersão social, a imersão na estrutura da rede e a imersão no contexto social (estruturas institucionais que governam o conteúdo dos relacionamentos). Para o autor, o embeddedness estrutural centra no modo em que a qualidade e a arquitetura da rede de relacionamentos de trocas materiais afetam a atividade econômica. Ao passo que outras formas de embeddedness, cognitivo, político e cultural, se assentam em perspectivas construcionistas e também contingenciais da ação econômica. Não obstante, essa discussão pode ser estendida para os mecanismos de embeddedness. Dacin, Ventresca e Beal (1999) resumem três mecanismos de imersão social com base construcionista: o mecanismo cognitivo, o mecanismo político e o mecanismo cultural.

O mecanismo cognitivo se relaciona a heurísticas e vieses na tomada de decisão, que têm origem em representações sociais, e não simplesmente na mente dos decisores, como resultado de um processo que ocorre no vácuo (e.g. evitação da incerteza). Nesses limites, a cognição é um processo social e coletivo de classificações e categorizações de grande espectro. 0 mecanismo político sustenta que esforços por poder e recursos moldam a atividade organizacional. Nessa lógica, as ações econômicas são moldadas por assimetrias de poder, sistemas legais, estado e classes políticas. 0 mecanismo cultural reflete significados e formas de entendimento compartilhadas, como, por exemplo, sistemas de crenças gerenciais sobre uma indústria (DACIN; VENTRESCA; BEAL, 1999).

A despeito das alternativas de análise a partir de diversas formas ou mecanismos de embeddedness, a literatura em geral destaca duas principais e mais contrastantes abordagens para a consideração do fenômeno, que refletem duas facetas para a análise da imersão social, os embeddedness estrutural e institucional. Na ênfase estrutural predomina a abordagem de redes.

No que tange às suas propriedades analíticas, essa perspectiva tem origem na psicologia, sociologia e na teoria das organizações, focalizando as relações sociais internas da organização, relações entre organizações ou no ambiente das organizações como um todo (POWELL; SMITH-DOERR, 1994). Nesse enfoque, interessa delimitar a posição do ator organizacional na rede, a qual revela funções de habilitação e coerção da ação dos atores organizacionais, ou então, identificar como determinado arranjo estrutural entre organizações gera benefícios e oportunidades (BURT, 1992).

Já o interesse da abordagem de redes que se debruça sobre a faceta institucional no nível da rede, com foco nas regras, normas e crenças e valores, entende a rede como forma de governança das ligações de interdependência em uma indústria, ou campo organizacional (POWELL; SMITH-DOERR, 1994). Essa interdependência é caracterizada por contratos relacionais, produção conjunta, e outras formas de alianças.

Em resumo, Powell e Smith-Doerr (1994) concluem defendendo uma posição que considere essas duas abordagens na busca de investigações que possam colocar em exame tanto a forma quanto o conteúdo da rede, buscando aprofundar a apreensão das ênfases estrutural e institucional, bem como as interseções entre as duas correntes de investigação.

Tal assertiva parece bastante razoável quando se considera que a ação social só pode ocorrer em uma arena social normativa, ou seja, em uma estrutura de relacionamentos, e a presença de uma configuração de atores forma uma arena que só é normativa e de natureza social quando existem instituições que regem o comportamento dos atores nessa rede.

\section{A ênfase estrutural nos relacionamentos interorganizacionais}

Como já foi mencionada, a emergência de novas formas organizacionais, especialmente a das redes estratégicas, tem revitalizado o interesse pelos relacionamentos interorganizacionais. A despeito da importância em se entender as facetas tanto estrutural como institucional dos relacionamentos interorganizacionais, assim como suas ligações de dependência ou interdependência, entre os pesquisadores de redes tem prevalecido a ênfase no exame da configuração social das redes.

Essa ênfase estrutural no estudo das redes sociais (GRANOVETTER, 1973; BURT, 1992, 2004; JACK, 2005) se debruça sobre o entendimento da natureza dos laços entre atores e seu potencial para desenvolver capital social.

0 expoente inicial dessa vertente foi Granovetter (1973), que discute a teoria dos laços fracos. Granovetter (1973) destaca a força dos laços fracos em condições de difusão de informações e oportunidade de mobilidade, demonstrando, por exemplo, a possibilidade de interações em pequenos grupos 
formarem padrões de larga escala em um nível institucional mais amplo.

Para Granovetter (1973), a força de um laço é caracterizada por uma combinação em termos de tempo, intensidade emocional, intimidade e reciprocidade. Por isso, os laços fracos são mais prováveis de promover difusão de novas informações entre membros de diferentes grupos em comparação aos laços fortes que tendem a ser concentrados dentro de grupos particulares. Nesse sentido, os laços fracos, que são frequentemente assumidos como mecanismos de alienação, são tomados por Granovetter (1973) como fatores cruciais para o alcance de oportunidades, novas informações e integração de indivíduos em outros grupos.

Em adição, deve-se ressaltar que a análise de redes sociais é evidenciada como uma forma de promover uma ligação entre os níveis micro e macro da teoria sociológica (GRANOVETTER, 1973). De acordo com esse autor é relevante se examinar as implicações em nível macro com origem nas interações no nível micro.

No plano organizacional, alguns pesquisadores têm buscado a ampliação desses e outros conceitos (BURT, 1992, 2004; JACK, 2005; UZZI, 1997). Uzzi (1997), por exemplo, sustenta a divisão primária em duas formas de estruturação das trocas entre organizações. Essas trocas podem se dar por meio de grupos de indivíduos com laços de trocas impessoais e que se deslocam continuamente entre agentes do mercado, ou por meio de redes de parceiros, que são sustentadas por relacionamentos sociais mais próximos, e que dão algum grau de estabilidade à configuração dos elementos da rede.

Os elementos chaves na diferenciação desses dois sistemas são a estrutura e a qualidade dos laços de troca. Pois esses elementos influenciam as expectativas e oportunidades com origem nas relações entre as organizações (UZZI, 1997). O primeiro sistema, com origem na formulação econômica neoclássica, se apresenta como o tipo ideal de mercado atomizado. A sua lógica se assenta no pressuposto de certa ausência de conteúdo sociorrelacional, por exemplo, reciprocidade e interação de natureza repetida, pois os parceiros de trocas são conectados por laços de natureza quase que estritamente econômica (arm'slenght ties), ou seja, os relacionamentos pessoais são frios e atomizados, e as trocas se caracterizam pela constante presença da motivação econômica autointeressada dos agentes envolvidos nesse relacionamento de mercado.

Na lógica oposta dos relacionamentos de mercado (arm's-lenght ties), os relacionamentos socialmente imersos (embedded relationships) são caracterizados pela presença de altos níveis de confiança e laços pessoais, que tornam os custos de monitoração inferiores em comparação aos relacionamentos baseados em contratos de mercado, a preferência pela cooperação para alcance de resultados de longo prazo ao invés da formação e sustentação de laços de dependência, e o desenvolvimento e previsibilidade de expectativas entre os atores sociais (UZZI, 1997).

A distinção fundamental entre esses dois sistemas de trocas é baseada em seus resultados para os membros envolvidos na troca. Se, nas relações de mercado o desempenho organizacional é facilitado por meio da dispersão dos negócios entre muitos competidores, reduzindo o poder de barganha de outros agentes, a criação de oportunidades é característica central das relações socialmente imersas, que, invariavelmente, são difíceis de serem replicadas por meio de mercados, contratos e estratégias de integração vertical. A despeito de esforços de natureza revisionista na economia, entre eles a Teoria dos Custos de Transação, Teoria da Agência, e a Teoria dos Jogos, essas áreas ainda reconhecem a influência da estrutura social na ação econômica de forma bastante superficial (UZZI, 1997).

Os laços socialmente imersos podem ser descritos pela sua natureza socialmente construída (UZZI, 1997). Esse mesmo autor sustenta que os relacionamentos de mercado poderão ser maiores em frequência, mas as relações socialmente construídas serão mais importantes.

Burt (1992) também direciona maior atenção para a estrutura da rede e sua influência sobre a estratégia e competitividade organizacional. Entretanto, o autor toma mais seriamente o papel das "falhas estruturais" (structural holes).

Burt (1992) sustenta que a taxa de retorno sobre os investimentos da organização é atrelada à estrutura social da arena competitiva. Cada organização tem uma rede de contatos em seu campo de atuação. É justamente a estrutura da rede de contatos de uma organização e a sua posição em tal rede que dá origem a vários tipos de capital e, consequentemente, à sua vantagem competitiva. 
A distinção mais usual entre os tipos de capital controlados por uma organização revela a existência de capital financeiro, capital humano e capital social. São as relações no interior e além dos limites da organização que configuram seu capital social.

A principal especificidade do capital social se assenta no controle das partes sobre ele. Diferentemente do que é sustentado na Visão Baseada em Recursos (BARNEY, 1996), o capital social não é propriedade de uma única parte em um relacionamento, e sim no fato de que só pode existir se for compartilhado por uma segunda parte na interação.

Nesses termos, Burt (1992, p. 9, tradução nossa) assevera que "o capital social é o árbitro final do sucesso competitivo". Isso é mais verdade nas situações de competição imperfeita. Nesse tipo de mercado, tão comum à realidade atual das organizações, a taxa de retorno sobre seus investimentos depende das relações nas quais o capital é investido. No domínio de ação de uma organização, as oportunidades alocadas para ela ou para as demais organizações de sua arena competitiva não são estabelecidas em termos de uma única dimensão das habilidades de uma organização. E, em mercados de competição imperfeita, é comum que o capital financeiro, e até o capital humano, sejam equiparáveis entre organizações. Contudo, um fator crucial no alcance de oportunidades se assenta, então, no capital social da organização. "O sucesso é determinado menos pelo o que você conhece do que por quem você conhece" (BURT, 1992, p. 10, tradução nossa).

A questão do capital social é vista em duas concepções e tratamentos diferentes. A primeira se assenta na associação bastante próxima dos recursos de um ator social com os recursos dos seus contatos e a variação nessa associação como uma variável dependente do tipo de relacionamento. 0 expoente dessa lógica na concepção do capital social é Granovetter (1973), com a sua metáfora dos laços fracos. A segunda concepção centra nas propriedades da rede como capital social, por exemplo, o tamanho da rede.

A diferença fundamental entre os dois tratamentos de capital social é que na primeira a estrutura da rede social é utilizada para identificar a homogeneidade entre atitudes e comportamentos, ao passo que, na segunda vertente, a estrutura da rede social é utilizada efetivamente na previsão de atitudes e comportamentos dos atores inseridos na rede. Enquanto a primeira linha de pesquisa centra no papel canalizador da rede, a segunda linha concebe a rede em si mesma como uma forma de capital social (BURT, 1992).

Dessas duas perspectivas no tratamento do capital social, o conceito pode ser entendido como os recursos dos contatos de um ator e a estrutura dos contatos na rede (BURT, 1992). "A primeira linha descreve quem você alcança, a segunda descreve como você alcança" (BURT, 1992, p. 12, tradução nossa).

Na ótica de Granovetter (1973) entende-se que a previsão da taxa de retorno depende do conhecimento dos recursos dos contatos de um ator. Já Burt (1992) pretende identificar parâmetros do capital social que possam ser generalizados além das especificidades dos indivíduos conectados por um relacionamento. Pois cada indivíduo conectado a outro poderia ter recursos diferentes, competências e rotinas organizacionais distintas. Outra razão é a correlação entre os dois componentes do capital social (recursos dos contatos e propriedades da rede). Em adição, a compreensão da estrutura da rede, em suas propriedades, permite reconstruir muito desse fenômeno e mais facilmente produzir uma explanação mais geral, sem incorrer nas idiossincrasias que concernem aos recursos dos membros que constituem uma rede.

Burt (1992) desenvolve sua teoria a partir do conceito de falhas ou buracos estruturais (structural holes). De acordo com o autor, as falhas estruturais na estrutura de uma rede de relacionamentos são responsáveis pelos benefícios de informação e controle. Essas falhas, ou buracos estruturais, são contatos não redundantes que apresentam como ligação apenas uma falha na estrutura da rede.

Contatos não redundantes apresentam uma falha na conexão entre eles. Essa falha é direta, simplesmente não existe nenhum contato direto entre os atores, ou uma das partes tem contatos que exclui o outro. Condições de não ausência são representadas pela coesão estrutural e equivalência estrutural. Coesão estrutural existe quando dois atores são conectados por um relacionamento. A equivalência estrutural ocorre quando dois atores têm os mesmos contatos na rede, mas não apresentam conexão direta. Apesar dessa ausência de conexão, a informação para ambos os atores sociais estruturalmente equivalentes é redundante em razão de manterem contatos com os mesmos outros atores da rede. A "equivalência estrutural concerne à conexão indireta por meio de contatos mútuos" de dois atores (BURT, 1992, p. 19, tradução nossa). 
Organizações em redes bem estruturadas aumentam sua probabilidade de alcançar vantagem competitiva em relação aos seus concorrentes, ao passo que a estrutura refina os benefícios de informação e controle (BURT, 1992).

Na mesma linha de Burt (1992), Gnyawali e Madhavan (2001) ampliam a consideração dos benefícios e limitações das estruturas das redes. 0 objetivo dos autores é compreender a dinâmica cooperativa e competitiva das organizações. Os autores desenvolvem um modelo multinível para explicação de como a estrutura da rede na qual a organização se insere, bem como as propriedades estruturais da organização, influenciam o fluxo de ativos, informações e status (condição social) entre os membros da rede.

Por meio dos relacionamentos cooperativos, organizações trabalham juntas para coletivamente melhorar seu desempenho, compartilhando recursos e se comprometendo a objetivos comuns em algum domínio. Ao mesmo tempo, parceiros também competem por tomar ações independentes em outros domínios para melhorar sua própria performance. Assim, cooperação e competição tomarão lugar, cada uma, em diferentes contextos.

O modelo dos autores é aplicado em situações em que existem simultaneamente competição e cooperação. É um modelo para especificar como propriedades das redes cooperativas influenciam a dinâmica competitiva. Dinâmica competitiva é definida como a probabilidade de uma organização iniciar uma ação competitiva e a probabilidade de um competidor responder àquela ação. Gnyawali e Madhavan (2001) exemplificam a influência da estrutura da rede de relacionamentos interorganizacionais examinando o efeito da centralidade, autonomia estrutural, equivalência estrutural, efeito direto da densidade da rede e efeito moderador da densidade da rede.

A alta centralidade (posição) conduz a uma maior velocidade e maior volume no fluxo de três ativos: recursos, informações e status (prestígio - condição social). Essa condição de alta centralidade leva a um maior status (condição social) e poder porque um ator que recebe muitos laços é considerado um ator de maior prestígio. Um ator central tem maior acesso a oportunidades e recursos, o que permite se beneficiar da assimetria positiva de recursos.

A alta centralidade também conduz a maior capacidade de ações competitivas, maior capacidade de obter informações para mais ações competitivas, maior capacidade para fortalecer suas capacidades competitivas, e mais acesso a informações para maiores previsões das ações competitivas de outros atores. A combinação de acesso a mais ativos, a um maior conjunto de informações e status e poder aumenta a probabilidade da organização central iniciar uma ação competitiva (GNYAWALI; MADHAVAN, 2001).

Essa posição superior e a posse dos melhores recursos que decorre também da posição, reduz a probabilidade de resposta competitiva das outras organizações da rede. Em relação aos fatores negativos, ocorre uma maior dependência de outras organizações, e, portanto, maior probabilidade de vazamentos de informações estratégicas.

A autonomia estrutural é extraída das falhas estruturais. A autonomia designa que o ator tem relacionamentos livres de falhas estruturais no seu próprio fim e rico em falhas estruturais no outro fim. Menor redundância de informações e alta qualidade de informações apresentam a oportunidade para uma organização controlar o fluxo de informações entre atores não conectados. Enquanto uma falha estrutural é uma propriedade da rede, a autonomia é uma propriedade do ator na rede.

A autonomia dá uma vantagem na falha estrutural. A organização estruturalmente autônoma coordena mais efetivamente e eficientemente fluxos de recursos, e os traduz em uma assimetria positiva de recursos que lhe dá vantagem competitiva. Daí, existe uma maior probabilidade da organização autônoma estruturalmente iniciar uma ação competitiva, e menor probabilidade dos competidores iniciarem uma resposta competitiva.

Quanto à equivalência, atores estruturalmente equivalentes têm um padrão de relações similar com os atores restantes da rede. É uma medida no nível da díade, de quão similar são os padrões de relacionamentos.

Organizações estruturalmente equivalentes podem apresentar ativos, informações e status (recursos) similares. Essas organizações tendem a não se confrontar. A assimetria de recursos é um importante preditor do ataque competitivo. Duas organizações estruturalmente equivalentes frequentemente têm acordo mútuo, tácito ou não, para não se confrontar. Nessas organizações, se uma é atacada a probabilidade de resposta é alta. Essa alta probabilidade de resposta reduz a probabilidade de uma delas iniciar uma ação competitiva (GNYAWALI; MADHAVAN, 2001).

Por sua vez, a densidade da rede é a extensão das interconexões entre os atores de uma rede. Quanto 
mais densa a rede, mais fácil o fluxo de informações e recursos. Quanto mais densa a rede, mais ela opera na lógica de um sistema fechado, no qual é mais fácil a manutenção de altos níveis de confiança, normas compartilhadas e padrões de comportamento. Granovetter (1985) afirma que a ameaça de sanções é mais efetiva em redes mais densas. A densidade amplifica a reputação da sanção, e é associada com uma menor variedade competitiva também. Quanto maior a densidade, menor é a probabilidade de ações competitivas. E quanto maior a densidade, maior a probabilidade de retaliação dos outros atores da rede no caso de ataque competitivo a um deles.

Quanto aos efeitos moderadores da rede, Gnyawali e Madhavan (2001) esclarecem que o aumento na densidade da rede diminui o principal efeito da centralidade, aumenta o principal efeito da autonomia estrutural e diminui os principais efeitos da equivalência estrutural.

Redes mais densas (diminuem a assimetria de recursos) enfraquecem o relacionamento positivo entre centralidade e probabilidade de ação. E enfraquecem o relacionamento negativo entre centralidade e probabilidade de resposta dos outros atores da rede.

Redes mais densas (tornam os recursos possuídos mais redundantes) fortalecem o relacionamento positivo entre autonomia estrutural e probabilidade de ação. E fortalecem o relacionamento negativo entre autonomia estrutural e probabilidade de resposta dos outros atores da rede.

Redes mais densas (aumentam o número de pares estruturalmente equivalentes) também enfraquecem o relacionamento negativo entre equivalência estrutural e probabilidade de ação. E enfraquecem o relacionamento positivo entre equivalência estrutural e probabilidade de resposta dos outros atores da rede (GNYAWALI; MADHAVAN, 2001).

Em face da relevância dessas e outras propriedades estruturais, alguns métodos, técnicas e medidas foram desenvolvidos na sociologia para a análise de redes, como é exposto no próximo tópico.

\section{A análise de redes e as medidas na ênfase estrutural}

O que se toma sob o rótulo de análise de redes é resultado do desenvolvimento de métodos apropriados para o exame de dados relacionais, que refletem as ligações entre atores, e permitem a construção e o mapeamento da estrutura na qual se dá a ação social.
Esses desenvolvimentos datam da década de 30, por meio de esforços de antropólogos e sociólogos baseados no conceito de estrutura social de RadcliffeBrown. Mas é a partir dos anos 70 que ocorreu um maior avanço de natureza técnica nos seus métodos e técnicas de análise (SCOTT, 2000).

A análise de redes sociais é considerada uma perspectiva distinta de pesquisa em razão da importância que assume os relacionamentos entre atores sociais. Nas palavras de Wassermann e Faust (1999, p. 4, tradução nossa):

A perspectiva de redes sociais abrange teorias, modelos e aplicações que são expressas em termos de conceitos ou processos relacionais. Ou seja, relações definidas por ligações entre unidades são um componente fundamental das teorias de redes.

Wassermann e Faust (1999) adicionam mais quatro princípios à noção dos conceitos relacionais: i) atores e suas ações são assumidas como interdependentes ao invés de dependentes; ii) laços relacionais entre atores são canais de fluxos de recursos; iii) modelos de redes com foco no ator individual concebem o ambiente estrutural como fonte de oportunidades e limitações à ação; e iv) modelos de redes concebem as estruturas sociais, políticas e econômicas, por exemplo, como padrões de relações entre atores.

No que concerne às medidas empregadas na análise de redes, tamanho, densidade e centralidade são os principais parâmetros de observação na caracterização de uma rede (HANNEMAN, 2001).

0 tamanho de uma rede é extraído por meio do número de conexões presentes (BURT, 1992). Outros atores entendem o tamanho da rede também pelo seu número de nós (HANNEMAN, 2001; SCOTT, 2000).

A densidade da rede se reflete por meio da força das ligações entre os atores de uma rede ou por meio de um coeficiente com variação de zero a um, que, dentro desses extremos, indica o grau de ligação entre os pontos de um gráfico. A principal função dessa medida é esclarecer quão distante está a soma total das ligações de uma rede da soma de todas as suas possíveis conexões (SCOTT, 2000).

Já a centralidade na análise de redes (centralidade do ator), a despeito das divergências e multiplicidade de medidas de centralidade em redes, comumente enfatiza as propriedades de centralidade local e global dos pontos que constituem as redes. A centralidade local (local centrality), ou de grau de um agente de 
uma rede, é admitida em face de um grande número de conexões mantidas com outros agentes. A centralidade global (closeness), ou de proximidade dos agentes, é percebida em razão da proeminência, ou posição estrutural estrategicamente significativa, de determinados atores em relação à estrutura da rede em sua totalidade. Na prática, essa medida contribui na separação de atores centrais e periféricos (SCOTT, 2000). Uma terceira medida de centralidade, de intermediação (betweenness centrality), mais complexa em sua aplicação, se dá a partir da extensão na qual um elemento em específico da rede está entre e faz a ligação de vários outros agentes. Atores com essa forma de centralidade estão entre um grande número de pares de outros agentes. Um ator com um grau de centralidade relativamente baixo irá exercer um papel de importância na mediação de outros agentes da rede. Essa medida permite representar a extensão na qual um agente pode desempenhar um papel de broker, portanto, com potencial de exercer controle sobre os outros elementos da rede (SCOTT, 2000).

Em relação à centralidade é importante não confundi-la com o conceito de centralização. A centralização não se refere a uma propriedade de um agente, ou de alguns atores, e sim da rede representada no gráfico sociométrico como um todo. Essa medida revela a coesão ou quanto a rede parece se configurar em uma estrutura mais fluída como um todo. Gráficos sociométricos serão mais ou menos centralizados ao redor de atores específicos ou conjunto de atores de uma rede (SCOTT, 2000).

Afora essas medidas mais tradicionais, alguns outros critérios de análise surgiram para contribuir no entendimento das implicações e explicações das configurações sociais, tais como a intensidade dos relacionamentos, importância e frequência.

A intensidade, diferentemente da densidade, reflete o quanto atores de uma rede estão inclinados a comportarem-se de acordo com normas e as suas obrigações, ou mais propensos a se entenderem livres para exercer seus direitos com outros atores (MITCHELL, 1976). Essa medida pode ser operacionalizada por meio do nível de comprometimento dos atores da rede com as outras organizações. A importância dos relacionamentos revela o quanto um ator social dá importância para o estabelecimento das suas relações com outras organizações (SCHMIDT; KOCHAN, 1977). Já a frequência é determinada pelos contatos entre atores num determinado espaço e período de tempo, entretanto, uma alta frequência de contatos não implica necessariamente em alta intensidade das relações (MITCHELL, 1976).

A discussão dessas medidas encerra o conjunto das principais técnicas na análise de redes. Uma maior variedade de formas de mensuração e tratamento de dados relacionais é encontrada em Scott (2000) e Wassermann e Faust (1999).

\section{Inovação}

A inovação pode ser definida como o uso produtivo de conhecimento que resulta no desenvolvimento e na introdução de novos produtos, processos e/ou serviços. Inovação é reconhecida como sendo o ponto central para riqueza econômica e bem-estar social, mas sendo classificada por ter complexidade, ambiguidade, risco e, por muitas vezes, ser influenciada pela velocidade das mudanças (DODGSON, 2000; DODGSON; VANDEMARK, 2000).

Entretanto, a inovação não se limita apenas a produtos e serviços. Uma organização pode ser inovadora sem necessariamente vender um produto tecnologicamente superior ao de seus concorrentes. Segundo Rios e Pinto (2004), as inovações, enfocadas como estratégia de mercado, devem possuir uma estreita relação com o cliente e um esforço sempre direcionado à identificação de suas necessidades. A rapidez e a qualidade na prestação dos serviços, a satisfação percebida pelos clientes e o aumento de receitas por parte das agências de turismo são alguns fatores fundamentais que determinam o êxito proporcionado pelas inovações tecnológicas. A capacidade de inovar constitui um dos fatores-chave para o sucesso de uma organização. Essa capacidade se traduz no potencial de transformar aprimoramentos tecnológicos de processo e produtos em realidade de mercado (RIOS; PINTO, 2004).

Na visão de Schumpeter (1982), para se alcançar o desenvolvimento econômico é necessário que se desenvolvam meios para integrar "materiais" e conhecimento. Para isto é necessário a introdução descontínua de novas combinações desses elementos, formando, portanto, o processo inovador. Na visão desse autor, no desenvolvimento econômico estão envolvidos cinco tipos de inovação: i) introdução de um produto novo ou uma mudança qualitativa em um produto existente; ii) novo processo de produção na indústria (que não precisa envolver um conhecimento novo); iii) a abertura de um novo mercado; iv) 
desenvolvimento de novas fontes de provisão para matérias-primas ou outras contribuições; e v) mudança organizacional.

Schumpeter (1982) aborda a inovação como a introdução de novos produtos, que mudam o ambiente competitivo que as empresas estão inseridas. Surge então a dúvida sobre como definir o que se quer dizer por meio da inovação. A definição amplamente usada pelos pesquisadores deriva daquela de Schumpeter (1982), que viu o processo inovador como consistindo em três fases: i) invenção (invenção de um processo de descoberta, de princípios técnicos novos); ii) inovação (inovação de um processo de desenvolvimento, de uma invenção de forma basicamente comercial); e iii) difusão (difusão de uma expansão de uma inovação em uso comercial).

A definição Schumpeteriana de inovação cria duas rotas principais para inovação: a empresa pode inovar implementando equipamento em um novo processo ou vendendo um produto novo adquirido de outra organização. É importante notar que para este tipo de inovação não se faz necessário nenhum intelectual inventivo ou esforço criativo. A organização pode inovar por meio da comercialização de novos produtos ou na implementação de um novo processo que desenvolveu com suas próprias atividades inventivas.

Para Tushman e Nadler (1986), inovação é a criação de algum produto, serviço ou processo que é novo para a unidade de negócio. Os autores distinguem dois tipos de inovação: inovação de produto, ou seja, quando há mudança no produto que a organização faz ou no serviço que ela fornece; e inovação de processo, que é a mudança na forma pela qual um produto é feito ou um serviço é fornecido.

Para organizações voltadas para a inovação, o conhecimento (NONAKA; TAKEUCHI, 1997) e a aprendizagem tornam-se fundamentais. Nonaka e Takeuchi (1997) defendem que as organizações bem-sucedidas são aquelas que criam novos conhecimentos, disseminam-nos amplamente por toda a organização e rapidamente os incorporam em novas tecnologias e produtos. Essas atividades, segundo os autores, definiriam as empresas que aprendem, cujo único negócio é a contínua inovação.

Para Daft (2003, p. 332), a inovação é "a adoção de uma ideia ou comportamento que são novos para o ramo de atividades, mercado ou o ambiente geral da organização". A primeira organização a introduzir um produto é considerada inovadora e as que copiam são as que adotam as modificações. Para fins de administração da mudança, contudo, os termos inovação e mudança são intercambiáveis porque o processo de mudança nas organizações tende a ser idêntico quer uma modificação seja feita cedo ou tarde em relação a outras organizações no ambiente (DAFT, 2003).

As inovações normalmente são assimiladas na organização mediante uma série de etapas ou elementos. Os membros da organização primeiro ficam a par de uma possível inovação, consideram sua adequação e depois avaliam e adotam a ideia. Os elementos necessários para uma mudança bem-sucedida são as ideias, a necessidade, a adoção e a implementação (DAFT, 2003). A inovação obrigatoriamente está relacionada a algum tipo de mudança. Para o autor, tais mudanças estão relacionadas a três aspectos: tecnologia, produtos e serviços e estratégia e estrutura. As mudanças em tecnologia são modificações no processo de produção da organização, incluindo sua base de conhecimentos e habilidades, que capacitam a competência distintiva. Essas mudanças abrangem as técnicas para gerar produtos ou serviços. Elas incluem métodos de trabalho, equipamentos e fluxo de trabalho. As mudanças nos produtos e serviços referem-se aos resultados em produtos e serviços de uma organização. Novos produtos incluem pequenas adaptações de produtos existentes ou linhas inteiramente novas de produtos. Os novos produtos normalmente são projetados para aumentar a participação de mercado ou para desenvolver novos mercados, consumidores ou clientes (DAFT, 2003).

\section{Efetividade de diferentes padrões estruturais dos relacionamentos interorganizacionais}

As redes interorganizacionais representam um fenômeno que possui uma maior capacidade de gerar alternativas de adaptação às pressões ambientais. Essa capacidade de se adaptar advém da inovação constante promovida pelas redes (ANDION, 2003).

Brass et al. (2004) concordam que as redes interorganizacionais trazem consequência em termos de inovação. Para os autores, a maior frequência de interações com outras organizações, principalmente clientes, estão positivamente associadas ao desenvolvimento de novos produtos.

Nas pesquisas que utilizam a perspectiva das redes sociais, tem se debatido com relação aos méritos de diferentes padrões estruturais de redes como 
determinantes dos resultados dos relacionamentos (BRASS et al., 2004; BURT, 1992; COLEMAN, 1988; POWELL; KOPUT; SMITH-DOERR, 1996; SODA; USAI; ZAHEER, 2004).

$O$ debate tem focado principalmente dois tipos de padrões estruturais: redes densas (COLEMAN, 1988) e aquelas ricas em buracos estruturais (BURT, 1992). Adicionalmente, os pesquisadores têm identificado as contingências por meio das quais um padrão estrutural é mais benéfico que outro: redes densas, nas quais predominam os laços fortes, geram confiança (COLEMAN, 1988); redes com buracos estruturais, nas quais existem poucas ligações diretas, ligam os atores a diferentes pontos da rede, permitindo o acesso a um conhecimento diverso (BURT, 1992). 0 estudo de Ahuja (2000) na indústria química mostrou que a taxa de registros e patentes aumentou quando as organizações tinham muitos laços entre si, indicando um efeito positivo entre o acesso a informações e a inovação, mas que buracos estruturais reduziram as taxas de inovação. Esses achados parecem suportar uma visão das redes densas, mas não suportam a visão dos buracos estruturais. Por outro lado, Baum, Calabrese e Silverman (2000), em um estudo com organizações de biotecnologia canadenses, mostraram que as redes que permitem acesso a informações não reduntantes têm um efeito positivo sobre a taxa de registros e patentes. Tais achados são corroborados por Ruef (2002), no qual os membros de equipes de desenvolvimento avaliaram suas próprias ideias como sendo mais inovativas se eles tinham ligações com diversas redes.

Brass et al. (2004) consideram que a literatura tem reconhecido o uso dos laços fortes e fracos para compartilhar conhecimento além dos limites organizacionais, particularmente se essas organizações não são competidores diretos. Nesse sentido, Powell, Koput e Smith-Doerr (1996) demonstraram que a existência de relacionamentos cooperativos entre as organizações de biotecnologia resultou em maior inovação. Um survey realizado por Yli-Renko, Autio e Sapienza (2001) constatou que as interações das organizações de base tecnológica com seus principais clientes e a obtenção de novos clientes por meio da rede de seus principais clientes tinham uma associação positiva com o desenvolvimento de novos produtos.

As redes interorganizacionais não modelam somente a inovação enquanto resultado, elas também podem trazer inovação em termos de recursos como os investimentos em pesquisa e desenvolvimento.
Em um estudo sobre alianças estratégicas entre organizações de telecomunicações, Soh, Mahoom e Mitchell (2004) constataram que a centralidade na rede estava relacionada com os investimentos em pesquisa e desenvolvimento.

Diante da discussão sobre o aspecto estrutural das redes apresentadas até aqui, é possível levantar algumas proposições a respeito dessas formas organizacionais em termos de inovação.

A alta centralidade (posição) conduz a uma maior velocidade e maior volume no fluxo de três ativos: recursos, informações e status (prestígio - condição social). Essa condição de alta centralidade leva a um maior status (condição social) e poder porque um ator que recebe muitos laços é considerado um ator de maior prestígio. Um ator central tem maior acesso a oportunidades e recursos, o que permite se beneficiar da assimetria positiva de recursos. Nesse sentido, tem-se que:

- P1 - A centralidade do ator em uma rede interorganizacional está positivamente relacionada com a capacidade de inovação em função do seu maior acesso a recursos, informações. Além disso, tais atores possuem acesso facilitado às inovações que surgirem na rede.

A autonomia estrutural é extraída das falhas estruturais. A autonomia designa que o ator tem relacionamentos livres de falhas estruturais no seu próprio fim e rico em falhas estruturais no outro fim. Menor redundância de informações e alta qualidade de informações apresentam a oportunidade para uma organização controlar o fluxo de informações entre atores não conectados. Enquanto uma falha estrutural é uma propriedade da rede, a autonomia é uma propriedade do ator na rede.

A autonomia dá uma vantagem na falha estrutural. A organização estruturalmente autônoma coordena mais efetivamente e eficientemente fluxos de recursos, e os traduz em uma assimetria positiva de recursos que lhe dá vantagem competitiva.

- P2 - A capacidade de inovação de atores com maior autonomia estrutural em uma rede interorganizacional é menos afetada pelos seus relacionamentos comparativamente a atores com menor autonomia estrutural.

Quanto à equivalência, atores estruturalmente equivalentes têm um padrão de relações similar com 
os atores restantes da rede. É uma medida no nível da díade, de quão similar são os padrões de relacionamentos. Organizações estruturalmente equivalentes podem apresentar ativos, informações e status (recursos) similares (GNYAWALI; MADHAVAN, 2001).

- P3 - Os atores estruturalmente equivalentes em uma rede interorganizacional tendem a possuir igual capacidade de inovação em função da similaridade de seus relacionamentos.

\section{Considerações finais}

A literatura sobre relacionamentos interorganizacionais tem reconhecido a importância das redes interorganizacionais como uma forma organizacional facilitadora do processo de inovação. Nesse sentido, este trabalho procurou enfocar o tema da inovação em redes interorganizacionais por meio de uma ênfase estrutural.

Pode-se considerar que existe certo consenso entre os pesquisadores sobre a efetividade de certos padrões estruturais. Dessa forma os atores mais centrais na rede gozam de maior capacidade de inovação; os atores com maior autonomia estrutural são menos dependentes dos relacionamentos para realizarem inovações; e os atores estruturalmente equivalentes possuem capacidade de inovação similar, conforme as proposições feitas.

Percebe-se, ainda, que o debate em relação ao efeito dos laços fracos e fortes e dos buracos estruturais permanece sem solução (BRASS et al., 2004). Vide, por exemplo, os resultados dos estudos de Ahuja (2000) em comparação aos achados de Baum, Calabrese e Silverman (2000) e Ruef (2002), os quais encontraram relações contraditórias em relação aos efeitos dos laços e dos buracos estruturais sobre as taxas de inovação.

Essa falta de consenso na literatura pode ter origem na ação de outros fatores sobre os efeitos das redes além do aspecto estrutural, pois as pesquisas têm tipicamente examinado os efeitos da estrutura sobre os resultados sem considerar o fator tempo (BURT, 2000). Considerando que uma forte e valiosa ligação possa diminuir ou aumentar durante o tempo, suscitando questionamentos sobre a influência de antigas e atuais estruturas sobre os resultados atuais dos relacionamentos em rede (SODA; USAI; ZAHEER, 2004).
Além disso, Powell e Smith-Doerr (1994) chamam a atenção para o fato de que atuais resultados refletem os efeitos dos padrões duradouros dos relacionamentos. Considerando o aspecto dinâmico das redes de relacionamento, por meio de sua constante mudança e evolução, a estrutura atual pode não explicar completamente os resultados (SODA; USAI; ZAHEER, 2004).

Além do fator tempo, é preciso ponderar que tanto a literatura sobre os laços fracos e fortes quanto a literatura sobre os buracos estruturais consideram os efeitos das redes apenas por meio dos aspectos estruturais. Nesse sentido, o contexto social presente nos relacionamentos pode explicar o tipo e o nível de inovação ligado ao contexto institucional e social.

Por fim, além de testar as proposições feitas neste ensaio, sugere-se pesquisas adicionais, preferencialmente empíricas, sobre os efeitos da densidade, laços e dos buracos estruturais sobre a inovação, considerando fatores como a duração dos relacionamentos e contexto social e institucional no qual eles estão envoltos.

\section{Referências}

AHUJA, G. Collaboration networks, structural holes, and innovation: a longitudinal study. Administrative Science Quarterly, v. 45, n. 3, p. 425-455, 2000.

ANDION, C. Análise de redes de desenvolvimento local sustentável. Revista de Administração Pública, v. 17, n. 5, p. 1033-1052, 2003.

BALESTRIN, A.; VARGAS, L. M. A dimensão estratégica das redes horizontais de PMEs: teorizações e evidências. Revista de Administração Contemporânea, v. 8, edição especial, p. 203-227, 2004.

BARNEY, J. B. Gaining and sustaining competitive advantage. Reading, Mass.: Addison Wesley, 1996.

BAUM, J. A. C.; CALABRESE, T.; SILVERMAN, B. S. Don't go it alone: alliance network composition and startup's performance in Canadian biotechnology. Strategic Management Journal, v. 21, n. 3, p. 267-294, 2000.

BRASS, D. J. et al. Taking stock of networks and organizations: a multilevel perspective. Academy of Management Journal, v. 47, n. 6, p. 795-817, 2004.

BURT, R. S. Structural holes: the social structure of competition. Cambridge: Harvard University Press, 1992. 
BURT, R. S. Decay functions. Social Networks, v. 22, p. 1-28, 2000.

BURT, R. S. Structural holes and good ideas. The American Journal of Sociology, v. 110, n. 2, p. 349-399, 2004.

CASTELLS, M. A sociedade em rede. São Paulo: Paz e Terra, 1999.

COLEMAN, J. S. Social capital in the creation of human capital. American Journal of Sociology, v. 94, p. 95-120, 1988.

DACIN, M. T.; VENTRESCA, M. J.; BEAL, B. D. The embeddedness of organizations: dialogue \& directions. Journal of Management, v. 25, n. 3, p. 317-356, 1999.

DAFT, R. L. Organizações: teoria e projetos. São Paulo: Pioneira Thomson Learning, 2003.

DODGSON, M. The management of technological innovation: an international and strategic approach. Oxford [England]; New York: Oxford University Press, 2000.

DODGSON, M.; VANDEMARK, S. Inovação e globalização na indústria de minerais australiana. Canberra: Centro de Administração Austrália Ásia, 2000.

GNYAWALI, D. R.; MADHAVAN, R. Cooperative networks and competitive dynamics: a structural embeddedness perspective. Academy of Management Review, v. 26, n. 3, p. 431-445, 2001.

GRANOVETTER, M. The strength of weak ties. American Journal of Sociology, v. 78, n. 6, p. 1360-1380, 1973.

GRANOVETTER, M. Economic action and social structure: o problem of embeddedness. American Journal of Sociology, v. 91, n. 3, p. 481-510, 1985.

GULATI, R.; NOHRIA, N.; ZAHEER, A. Strategic networks. Strategic Management Journal, v. 21, n. 3, p. 203-215, 2000.

HANNEMAN, A. R. Introduction to social network methods. Riverside: University of California, 2001.

JACK, S. L. The role, use and activation of strong and weak network ties: a qualitative analysis. Journal of Management Studies, v. 42, n. 6, p. 1233-1259, 2005.

JARILLO, J. C. On strategic networks. Strategic Management Journal, v. 9, n. 1, p. 31-41, 1988.

MITCHELL, J. C. The concept and use of social networks. In: EVAN, W. M. Interorganizational relations. Pensilvania: University of Pensilvania Press, 1976.
NEUMAN, L. W. Social research methods: qualitative and quantitative approaches. Boston: Allyn \& Bacon, 1997.

NONAKA, I.; TAKEUCHI, H. Criação do conhecimento na empresa. Rio de Janeiro: Campus, 1997.

OLIVER, C. Determinants of interorganizational relationships: integration and future directions. Academy of Management Review, v. 15, n. 2, p. 241-265, 1990.

OLIVER, C. The institutional embeddedness of economic activity. In: SHRIVASTAVA, P.; HUFF, A. S.; DUTTON, J. E. (Ed.). Advances in strategic management. Greenwich, Connecticut: Jay Press, 1996. v. 13, p. 163-186.

POWELL, W. W.; KOPUT, K. W.; SMITH-DOERR, L. Interorganizational collaboration and the locus of innovation: organization and learning in biotechnology. Administrative Science Quarterly, v. 41, n. 1, p. 116-145, 1996.

POWELL, W. W.; SMITH-DOERR, L. Networks and economic life. In: SMELSER, N. J. R.; SWEDBERG, R. Handbook of economic sociology. Princepton: Russell Jage Foundation, 1994. p. 367-402.

RIOS, J. A. D.; PINTO, J. S. Indicadores de inovação. Revista de Administração Nova Odessa, v. 1, n. 1, p. 61-67, 2004.

RUEF, M. Strong ties, weak ties and islands: structural and cultural predictors of organizational innovation. Industrial and Corporate Change, v. 11, n. 3, p. 427-449, 2002.

SCHERER-WARREN, I. Cidadania sem fronteiras: ações coletivas na era da globalização. São Paulo: Hucitec, 1999.

SCHMIDT, S. M.; KOCHAN, T. A. Interorganizational relationships: patterns and motivations. Administrative Science Quarterly, v. 22, n. 2, p. 220-234, 1977.

SCHUMPETER, J. A. Teoria do desenvolvimento econômico: uma investigação sobre lucros, capital, crédito, juro e o ciclo econômico. São Paulo: Abril Cultural, 1982.

SCOTT, J. Social network analysis. London: Sage, 2000.

SODA, G.; USAI, A.; ZAHEER, A. Network memory: the influence of past and current networks on performance. Academy of Management Journal, v. 47, n. 6, p. 893-906, 2004.

SOH, O.; MAHOOM, I.; MITCHELL, W. Dynamic inducements in R\&D investment: market signals and network locations. Academy of Management Journal, v. 47, p. 907-917, 2004. 
WASSERMAN, S.; FAUST, K. Social network analysis. Cambridge: Cambridge University Press, 1999.

WILLIAMSON, O. E. Markets and hierarchies. New York: The Free Press, 1985.

YLI-RENKO, H.; AUTIO, E.; SAPIENZA, H. J. Social capital, knowledge acquisition, and knowledge exploitation in young technology-based firms. Strategic Management Journal, v. 22, p. 587-613, 2001.

UZZI, B. Social structure and competition in interfirm networks: the paradox of embeddedness. Administrative Science Quarterly, v. 42, n. 1, p. 35-67, 1997.

Recebido: 04/03/2011

VENKATRAMAN, N.; SUBRAMANIAM, M. Theorizing the fuReceived: 03/04/2011 ture of strategy: questions for shaping strategy research in the knowledge economy. In: PETTIGREW, A.; THOMAS, H.; WHITTINGTON, R. (Ed.). Handbook of strategy and maAprovado: 18/04/2011 nagement. London: Sage, 2002. p. 98-112. 